\title{
EDITORIAL
}

\section{Teaching Tips-A new series in JGIM}

\author{
Brent C. Williams, MD, MPH' and Richard M. Hoffman, MD, MPH² \\ 'Division of General Medicine, Department of Internal Medicine, University of Michigan, Ann Arbor, Ml 48109, USA; ${ }^{2}$ New Mexico VA Health \\ Care System, University of New Mexico School of Medicine, Albuquerque, NM, USA.
}

J Gen Intern Med 23(1):112-3

DOI: $10.1007 / \mathrm{s} 11606-007-0375-1$

(c) Society of General Internal Medicine 2007

$\mathrm{O}$ sler once said of medicine, "Life is short, the art is long." Like clinical medicine, clinical teaching involves both science and art. The science of clinical teaching is growing at a steady, albeit frustratingly slow, pace. One important mission of JGIM is to increase the scientific understanding of clinical teaching by publishing high-quality research on clinical education. However, the art of clinical teaching is more subjective, involving the life stories, values, and interpersonal interactions of teachers, learners, and patients ${ }^{1}$. The art of medicine is a key source of inspiration for clinical teachers. When teachers get together over coffee (or something stronger), they are more likely to swap moving stories of powerful teaching encounters than the latest research findings.

As every clinical educator knows, bringing the best art and the best science into particular teaching encounters is challenging. Subtle nuances matter, such as the learning climate; the receptivity, interests, and needs of the learner, and the knowledge and interaction style of the teacher. As evidenced by discussions around the Innovations in Education series in JGIM and presentations at the national SGIM meeting, clinical educators are endlessly interested in trading "secrets" of what does and does not work in creating lively, creative teaching/ learning encounters. In this spirit, JGIM introduces a new series of articles-Teaching Tips-whose overall goal is to provide practical, specific, "how to" suggestions for teaching from experienced educators that other clinical educators can try out and adapt to their own settings.

The idea for a Teaching Tips series was sparked by a proposal from the Evidence Based Medicine Teaching Scripts Working Group (herein termed the EBM Teaching Working Group), a group of EBM teachers from many institutions who have extensive experience in teaching EBM to clinical learners. About a year ago, the EBM Teaching Working Group, headed by Dr. Peter Wyer, approached JGIM with a proposal to write a series of articles with practical suggestions to clinical educators on how to teach specific topics in EBM. Previous papers in the series had appeared in the Canadian Medical Association Journal ${ }^{2}$ and had been positively received by readers of that journal.

The EBM Teaching Tips series makes its first appearance in this issue of JGIM in an article on how to teach about likelihood

Published online September 20, 2007 ratios as applied to diagnostic tests ${ }^{3}$. As a long-time teacher of likelihood ratios, with plenty of blank stares and stony silences among learners under his belt, one of us $(\mathrm{BCW})$ now routinely incorporates the tips described in this article in his teaching. The EBM Teaching Tips are different from other types of JGIM articles in at least 2 respects. First, they are intended for immediate and practical application, and so adopt a script-like tone of great detail-providing specific examples, phrases, diagrams, and nonverbal behaviors to teach particular concepts. This tone will undoubtedly be new, and perhaps feel foreign, to some readers. Second, they are based on the field experiences of seasoned EBM teachers rather than quantitative research; they make no scientific claim to generalizability or outcomes. As a consequence of field testing, they have undergone explicit review and modification based on extensive use.

To foster the uptake and improvement of the EBM Teaching Tips, the Working Group has created a set of Web-based video demonstrations and discussion forums for the specific tips. These materials are available as extra supplementary material to the Teaching Tips articles on the JGIM web site. JGIM editors look forward to providing the forum for this experiment in communication among clinician educators and envision readers actively engaging in open and specific "shop talk" to refine and improve teaching around topics of common interest.

The future Editors for this series (Richard M. Hoffman, MD; Jeffrey Jackson, MD, MPH; and W. Scott Richardson, MD) envision Teaching Tips to include topics and authors other than Evidence-Based Medicine (traditionally defined) and the EBM Teaching Working Group. Encouraged by our review of the EBM Teaching Tips series, we invite clinician educators to submit articles for the Teaching Tips series. Like the EBM Teaching Tips, submitted articles will be subject to peer review and must meet specific content and formatting requirements that are described in the Instructions to Authors. In general, Teaching Tips articles will be expected to: (a) focus on topics directly related to clinical care by physicians of adult patients, (b) include a literature-based rationale for the importance of the topic, (c) be appropriate for medical students, residents, fellows, or faculty in clinical or small group teaching settings, (d) relate to a topic commonly taught by a large number of clinician educators, (e) include specific suggestions on teaching methods, and (f) describe the results of field testing and subsequent refinement of the teaching tips. Undoubtedly, our ideas and requirements for the series will change as we interact with authors of potential Teaching Tips.

Every clinician educator has had powerful experiences and strong opinions about the context and skills of clinical teaching - seeing the anxious look, the painful silence, or the dawning 
of insight and enthusiasm in our learners is simultaneously motivating and humbling. We look forward to creating an open and ongoing dialogue with, and among, our readers to describe and improve the art and science of clinical education.

Corresponding Author: Brent C. Williams, MD, MPH; Division of General Medicine, Department of Internal Medicine, University of Michigan, Ann Arbor, MI 48109, USA (e-mail: bwilliam@umich.edu).

\section{REFERENCES}

1. Palmer PJ. The Courage to Teach: Exploring the inner landscape of teacher's life. San Francisco, CA: Jossey-Bass, Inc; 1998.

2. Wyer PC, Keitz S, Hatala R, Hayward R, Barratt A, Montori V, Wooltorton E, Guyatt G. Tips for learning and teaching evidence-based medicine: Introduction to the series. Can Med Assoc J 2004;171:347-8.

3. Richardson WS, Wilson MC, Keitz SA, Wyer PC for the EBM Teaching Scripts Working Group. Tips for teachers of evidence-based medicine: Making sense of diagnostic test results using likelihood ratios. J Gen Intern Med 2007 (in this issue). 